\title{
POESÍA Y POÉTICA EN ALFONSO REYES
}

\author{
Mas queda otro sendero todavía \\ que purga la codicia y la miseria: \\ la ruta vertical, la poesía. \\ ALFONSO REYES, "Materialismo histórico"
}

Pocos escritores de Hispanoamérica han sido tan aplastados bajo el peso asfixiante de una fama institucionalizada y oficial, como lo ha sido Alfonso Reyes. Le ha tocado la peor suerte que puede tener un escritor: ser poco leído. Más que revelar, los conocidos rótulos -el mexicano universal, el humanista generoso, el estudioso de erudición enciclopédica- sólo parecen haber servido para ocultar y enmascarar al escritor y su obra. No es que los rótulos sean equivocados sino sobre todo desgastados, aceptados automática y acríticamente, sin pensar en su significado real.

Efectivamente la vasta obra multifacética de Reyes encarna la tentativa por abarcarlo todo: crítica literaria, poesía, crónica, teoría literaria, narrativa, ensayos literarios y culturales, artículos, tratados, retratos, memorias y crítica cinematográfica, para mencionar algunos de los géneros ensayados. A todo esto habría que agregar las traducciones y otro territorio inmenso que apenas se va revelando en todas sus dimensiones: el epistolario que Reyes sostuvo con muchas de las grandes figuras literarias de su tiempo.

Aunque la diversidad de intereses y de cauces de expresión parece sugerir dispersión, nada hay más alejado de la verdad. Existe una profunda coherencia en la escritura del mexicano, una unidad subyacente que se cifra en el desmesurado proyecto de apro- 
piarse de la cultura occidental, asimilarla y recrearla para proveer las bases de una cultura auténticamente americana. Obra de fundación cultural que postula la necesidad de que el intelectual no sea el receptor pasivo sino un sujeto activo que selecciona y sintetiza por derecho propio. Esta actitud es el modelo moderno más importante para las tareas paralelas de Jorge Luis Borges y Octavio Paz. Hay que agregar, por supuesto, que este esfuerzo fundador exigió la transformación de la prosa castellana en un instrumento flexible, dinámico y ágil. Es bien conocida la opinión de Borges en el sentido de que Reyes es el creador de "la prosa más admirable de la lengua castellana"'.

Pero entre todas las facetas de Reyes, una de las menos conocidas y menos valoradas es la de Reyes poeta. Se señala con frecuencia que la mejor poesía del autor está en su prosa. Este justo elogio esconde sin embargo una subrepticia descalificación del poeta en verso. De hecho, desde muy temprano empieza la polémica en cuanto al verdadero estatuto de Reyes como poeta. "Al fin - escribió Pedro Henríquez Ureña en 1927- el público se convence de que Alfonso Reyes, ante todo, es poeta"'2. Desgraciadamente, ni entonces ni ahora ha existido el consenso anhelado por el compañero ateneísta.

En 1923, por ejemplo, el joven Xavier Villaurrutia publicó una recensión, poco conocida hoy, de Huellas, el primer libro de versos de Reyes. La nota, benévolamente calificada años más tarde por Reyes como "algo reticente"', resulta ser, al contrario, agresivamente explícita:

No es Alfonso Reyes un gran poeta; no lo fue tampoco en sus años mejores; sus poemas de entonces, repetidos en antologías y revistas, nos servían para recordar y amar al otro Alfonso Reyes que escribía ensayos perfectos y animados, que disertaba con una fluidez no acostumbrada sobre motivos helenos, como glosaba letras latinas y sajonas, antiguos y modernos [...]

Literato de todas las horas no puede dejar de ser un poeta cere-

1 Jorge Luis Borges, "Cómo conocí a Alfonso Reyes", Sábado, supl. de Unomásuno, 17 de junio de 1989 , p. 2.

${ }^{2}$ Pedro Henríquez Ureña, Seis ensayos en busca de nuestra expresión, en Obra crítica, ed. Emma Susana Speratti-Piñero, pról. de Jorge Luis Borges, FCE, México, 1960, p. 292.

${ }^{3}$ Alfonso Reyes, "Historia documental de mis libros. XIII. El año de 1922 (continuación)", UMex, 12 (1957), p. 16. 
bral. Su clasicismo carece de la inquietud romántica que requiere el artista moderno $[\ldots]^{4}$.

Las críticas de Villaurrutia - bastante petulantes e injustas si se piensa que se trataba del primer libro de versos de Reyeshan sido repetidas después por varios críticos y escritores ${ }^{5}$. Pero frente a estas dudas o descalificaciones existe otro punto de vista, inaugurado por Henríquez Ureña y reiterado con pasión en 1948 por Francisco Giner de los Ríos:

Su poesía [...] es algo así como el centro de la esencia última de su obra [...] sí creo que Reyes es ante todo poeta, y que todo lo suyo [...] está informado directamente por su inteligencia poética y precisamente por ella ${ }^{6}$.

Más recientemente, Octavio Paz ha expresado la necesidad de releer y redescubrir a Reyes como poeta ${ }^{7}$.

Conviene, pues, plantear algunas preguntas: ¿por qué es difícil leer a Reyes como poeta?, ¿cuáles son las causas de las reticencias, dudas y reservas de sus detractores? Creo que hay varias razones. En primer lugar existe una dificultad de tipo puramente convencional: la poesía de Reyes no cabe dentro de ningun movimiento, tendencia o escuela. Si bien coincide en ciertos momentos con una tendencia dominante, no se puede decir que pertenezca orgánicamente ni al modernismo ni a la vanguardia ${ }^{8}$. Es más: no

4 Xavier Villaurrutia, "Huellas de Alfonso Reyes", La Falange, julio de 1923 , p. 249.

5 Véase, por ejemplo, A. Silva Villalobos, "Una obra poética", Metáfora, México, 1955, núm. 5, 6-10. El autor se muestra singularmente hostil en sus opiniones acerca de la poesía de Reyes: "Ante nosotros está el versificador quien confunde, casi siempre, el oficio de medir y rimar versos con el de hacer poesía", p. 7. Más adelante agrega: "Es difícil analizar poéticamente una obra que no es capaz de conmover a ningún sentimiento interior profundo", p. 9.

6 Francisco Giner de los Ríos, "Invitación a la poesía de Alfonso Reyes", CuA, 42 (1948), 252-253.

7 "De Octavio Paz" [fragmento de una entrevista], La Nación, Buenos Aires, Sección $4^{a}$ (Letras/Artes/Ciencia), 21 de mayo de 1989, p. 1. Refiriéndose a Reyes, Paz opina: "Fue un verdadero poeta y le debemos algunos poemas de verdad excepcionales. Entre ellos un gran texto en la tradición de Mallarmé y Valéry: Ifigenia cruel. La crítica de nuestra lengua ha ignorado al Reyes poeta. Al poeta en verso y al poeta en prosa. Gran pecado, miopía imperdonable. Entre los poetas de su generación no fue inferior ni a López Velarde ni a Gabriela Mistral"'.

${ }^{8}$ En lo que sigue siendo el mejor artículo dedicado exclusivamente a la 
parece tener ni antecesores ni sucesores directos en la poesía mexicana, como lo han observado los autores de la antología Poesía en movimiento ${ }^{9}$. Además, el propio escritor señaló, en una carta a Tomás Navarro, su inconformidad con la clasificación de su poesía dentro del modernismo:

Yo comprendo la necesidad de clasificar por épocas. Pero, en cuanto a la tendencia estética y poética, ¿acomodo yo dentro del modernismo, contra el cual quise reaccionar desde mis primeros versos? Yo entiendo que en la Métrica se llama modernismo a una época y no a una escuela. Porque yo creo que no tengo escuela. Hasta eso ha hecho que mi poesía no sea muy bien entendida $[\ldots]^{10}$.

Para los que no buscan entender sino encasillar, Reyes - como todo auténtico poeta- resulta ser inasible. También se ha lamentado la falta de una obra maestra, sin fijarse en el extraño esplendor de Ifigenia cruel, ambicioso poema dramático que constituye, en palabras de Octavio Paz, "su obra poética más perfecta"11.

Entre las dudas más comprensibles, destaco la aparente indiferencia de Reyes ante las vanguardias del siglo xx. Esta reserva proviene de una postura clasicista que parece, a todas luces, anacrónica en nuestro siglo. Reyes no cree en las doctrinas de la ruptura, ni en la reducción del poema a la metáfora; no tienen gran

poesía de Reyes, Eugenio Florit traza los puntos de contacto entre el mexicano y diferentes tendencias estéticas, tales como el modernismo, el vanguardismo, el negrismo, el barroquismo y rasgos de lo tradicional, "Alfonso Reyes: vida y obra. II. La obra poética", RHM, 22 (1956), 224-248.

${ }^{9}$ Véase Poesía en movimiento. México, 1915-1966, sel. y notas de Octavio Paz, Alí Chumacero, José Emilio Pacheco y Homero Aridjis, pról. de Octavio Paz, Siglo XXI, México, 1966, p. 412.

10 Fragmento de una carta de Reyes a Tomás Navarro, incluido en el Apéndice a Concha Meléndez, Moradas de poesía en Alfonso Reyes [1973], en Obras completas, t. 5, Instituto de Cultura Puertorriqueña, San Juan de Puerto Rico, 1974, pp. 650-651. Reyes se refiere, en su carta, al clásico manual de Tomás NaVarro, Métrica española; reseña histórica y descriptiva, Syracuse University Press, Syracuse, NY, 1956. Navarro había clasificado a Reyes bajo el rubro del modernismo, basándose en el criterio de la versificación y las formas métricas empleadas.

11 Octavio Paz, "El jinete del aire" [1960], en Puertas al campo [1966], Seix Barral, Barcelona, 1972, p. 51. Entre los críticos que lamentan la falta de una obra maestra, destaco a ENRIQUe ANDERSON IMBERT, quien se refiere a Reyes como "un clásico de nuestra historia literaria que, sin embargo, no dejó grandes libros orgánicos"' (Historia de la literatura hispanoamericana, FCE, México, 1954, t. 2, p. 141). 
importancia en su poesía la problematización del lenguaje, ni el cuestionamiento del poder significativo de las palabras (y esto a pesar de ser un ávido lector y crítico de Mallarmé, uno de los padres de la vanguardia experimental) ${ }^{12}$. En suma, brilla por su ausencia uno de los rasgos centrales de la tradición poética moderna desde Blake y los románticos, pasando por Rimbaud y los poetas malditos, hasta llegar a la vanguardia: me refiero a la noción de la poesía como desmesura, como transgresión violenta de las normas establecidas, como intento utópico de fundar un orden nuevo a través del arte.

Inútil buscar en Reyes esta idea de la poesía como aventura, acción o transgresión. Como lo ha observado muy bien Gabriel Zaid, los lectores modernos, al leer a Reyes, no encontramos algo que buscamos, algo que forma parte de nuestras preconcepciones y expectativas, que siguen siendo fundamentalmente románticas ${ }^{13}$. Se frustra la esperanza de una exploración de las capas profundas y ocultas del ser, la esperanza de toparnos con una intensidad destructiva. Hay que reconocer que la temperatura de la poesía del mexicano es mucho más baja.

Su actitud ante las tradiciones anteriores no es polémica ni combativa sino de integración e incorporación. Ubicadas ya en la perspectiva de la distancia histórica las conquistas del vanguardismo, la actitud ante la tradición en Reyes surge como una postura saludable porque busca recuperar y recrear tradiciones anteriores, ocultas u olvidadas. Sabemos ahora que el antagonismo vanguardista hacia el pasado en bloque, casi nunca pasó de ser una posición programática y, de hecho, varios de los movimientos de ruptura promovieron activamente la recuperación de tradiciones alejadas o despreciadas. Antes que la Generación de 1927 en España, Reyes había sido uno de los iniciadores - desde 1910 - de la revaloración de Góngora ${ }^{14}$.

${ }^{12}$ Sobre esta aparente falta de correspondencia entre las predilecciones del crítico y la práctica del poeta, MAX AUB opinó: "Lo curioso es que Reyes, tan al corriente y en la corriente, no refleja en su obra poética el gusto por la poesía que defiende y define en prosa: Mallarmé, Valéry y Góngora, el de las Soledades" ("Alfonso Reyes, segun su poesía" [1953], en Páginas sobre Alfonso Reyes, (1946-1957), Universidad de Nuevo León, Monterrey, 1957, t. 2, p. 278).

${ }^{13}$ Gabriel ZaID, "Dudas sobre el poeta Alfonso Reyes", en Leer poesía, $2^{\mathrm{a}}$ ed., corr. y aum., J. Mortiz, México, 1976, pp. 9-10.

${ }^{14} \mathrm{El}$ primer ensayo de Reyes sobre el poeta barroco se titula "Sobre la estética de Góngora”. Fue, originalmente, una conferencia leída en una sesión del “Ateneo de la Juventud"', el 26 de enero de 1910. El autor lo recogió 
Creo que lo anterior nos lleva a una comprensión déla estética clasicista de Reyes. Las fuentes de esta estética están en la formación intelectual del autor. Henríquez Ureña, de nuevo, pone el dedo en la llaga al notar que la cultura de Reyes era un compromiso entre el positivismo, del cual aceptó la disciplina y el rigor pero rechazó la filosofía, y las filosofías de la intuición, aceptadas críticamente y a las cuales opuso su formación positivista: "resistió mejor que otros a la fascinación del irracionalismo. El impulso y el instinto, en él, llaman a la razón para que ordene, encauce y conduzca a término feliz" 15 .

Muy lejos del clasicismo polémico de Jorge Cuesta, el clasicismo de Reyes va más allá de la afición helénica y la erudición del humanista para convertirse en una auténtica visión del mundo: una filosofía, una estética y una moral. ¿Cuál es esta visión del mundo? En el universo hay discordia y caos, pero a través del arte el hombre puede restablecer, por un instante eterno, "el equilibrio esencial de las cosas" 16 . Octavio Paz ha identificado las palabras clave de esta visión como pacto, acuerdo, mesura, proporción, acorde, concordia: "En una época de discordia y uniformidad - dos caras de la misma medalla- Reyes postula una voluntad de concierto, es decir, un orden que no excluya la singularidad de las partes"17.

En la poesía de Reyes se palpa este equilibrio entre razón e intuición, cerebro y pasión, intelecto y sentimiento. Hay siempre un principio de integración superior, una actitud que limita todo exceso. Al reconocer el límite de la medida, el poeta no sólo reconstruye el orden natural sino que descubre su propio lugar en el todo y comprende que su libertad es la libre aceptación de una fatalidad.

Para el temperamento clásico no hay emociones que amenazan con romper los diques de la forma y desbordarse por su fuerza interna, sino que todo encuentra su justa medida: la forma es siempre ceñida, mesurada y equilibrada. Y no es que le falte pasión sino que lo emotivo está controlado y ordenado por la razón y el intelecto hasta que todo cuaje en la perfección de la forma. ¿No hay tensión, entonces, en la poesía de Reyes? En el sentido

en su primer libro, Cuestiones estéticas [1911], y se puede consultar hoy en $A R O C$, t. 1, pp. 61-85.

${ }^{15}$ P. HenríQuez UReña, op. cit., pp. 298-299.

${ }^{16}$ Ibid., p. 298.

17 O. PAZ, "El jinete del aire", p. 57. 
de una oposición violenta entre términos irreconciliables, no la hay, pero sí hay una tensión resuelta en la forma: una catarsis estética y vital. La estética se confunde aquí con una ética, mientras que el rigor desemboca de forma natural en un ascetismo moral. Así lo expresa Reyes:

Escribir es como la respiración de mi alma, la válvula de mi moral. Siempre he confiado a la pluma la tarea de consolarme o devolverme el equilibrio, que el envite de las impresiones exteriores amenaza todos los días. Escribo porque vivo. Y nunca he creído que escribir sea otra cosa que disciplinar todos los órdenes de la actividad espiritual, y, por consecuencia, depurar de paso todos los motivos de la conducta ${ }^{18}$.

Además, hay que señalar que como concepto crítico, la tensión es otra invención de nuestra modernidad. Aunque el concepto fue proclamado como esencial a toda poesía por la nueva crítica angloamericana, apenas es necesario recordar que durante largos periodos y en diferentes culturas, ha existido una poesía exenta de tensión y de conflictos irreconciliables.

Hay dos elementos más en la poética de Reyes que sugieren el carácter anacrónico de su propia obra en verso. La primera idea está resumida muy bien por el autor en una carta a Emir Rodríguez Monegal: "Quiero que la literatura sea una cabal explicitación[... ]"19. La imprecisión se ve siempre, en Reyes, como vaguedad retórica. Así, en el ensayo "Jacob o idea de la poesía", el poeta desdoblado en crítico escribe:

Toda imprecisión es un estado de ánimo anterior a la poética [ . . . ] el poeta debe ser preciso en las expresiones de lo impreciso. Nada se puede dejar a la casualidad. El arte es una continua victoria de la conciencia sobre el caos de las realidades exteriores ${ }^{20}$.

Pero si todo es precisión, claridad y transparencia, el lector actual se preguntará ¿dónde quedan la ambigüedad y la polisemia,

18 “Alfonso Reyes", en Emmanuel Carballo, Protagonistas de la literatura mexicana [1965], Ediciones del Ermitaño-SEP, 1986, p. 142.

${ }^{19}$ Fragmento de una carta a Emir Rodríguez Monegal, fechada el 31 de agosto de 1953, incluido por Reyes en la "Justificación" a Romances sordos, en Constancia poética, $A R O C$, t. 10, p. 463. En adelante, todas las referencias que se dan en el texto entre paréntesis serán a esta edición.

20 Alfonso Reyes, "Jacob o idea de la poesía" [1933], en La experiencia literaria [1942], recogido en $A R O C$, t. 14, p. 103. 
características esenciales de nuestra poética moderna?

Ahora bien, del justificado escepticismo del autor en cuanto a la libertad total en el arte, y de su saludable noción de que la disciplina, lejos de ser una cárcel de constricciones y de reglas inquebrantables, constituye un conjunto de estímulos positivos que permiten la superación y la perfección, se desprenden consecuencias duales. Por un lado, se destaca el efecto positivo de subrayar que en arte es imposible prescindir de toda norma y que la auténtica libertad implica el reconocimiento de los límites: "el verdadero artista es el que se esclaviza a las más fuertes disciplinas, para dominarlas e ir sacando de la necesidad virtud" "21. Pero el corolario negativo de esta doctrina de la contención y el control, es que difícilmente permite una exploración de aquellas zonas de la experiencia humana que no se dejan someter a un régimen de claridad y explicitación. La poética de Reyes parece excluir la posibilidad de una poesía de buceos oníricos o psicológicos. Su desconfianza en los poderes irracionales desemboca en una automutilación.

La segunda idea, expresada varias veces por el poeta, trata del carácter autobiográfico de toda poesía. Recordando a su admirado Goethe, Reyes afirmó que "toda poesía es poesía de ocasión" 22 y, en otro lugar, recalcó: "por mi parte, no distingo entre mi vida y mis letras"' (p. 463). Incluso llegó a decir: "Mi modesta obra lírica, por ejemplo, sería falseada si no se la aprecia en relación con la fecha de cada poema''23. Recordemos también el cuidado que siempre tuvo Reyes por precisar el lugar y la fecha de cada una de sus composiciones. Sabemos que en casi todas las culturas la poesía ha desempeñado por mucho tiempo un papel funcional o instrumental ("ancilar" diría Reyes): poesía ritual o poesía de circunstancias. La noción del poema como universo auto-

${ }^{21}$ Ibid., p. 101. Vale la pena agregar que esta concepción del proceso de creación como algo inconcebible sin la disciplina y el rigor de la parte racional y lúcida del ser, explica la violenta oposición de Reyes a la doctrina surrealista de la escritura automática, que el autor ridiculiza sin nombrarla explícitamente: "Y aun hay malos instantes en que la obra poética pretende arrogarse las funciones de la escritura mediumnímica o sonambúlica; en que el poema usurpa la categoría de documento psicoanalítico o confesión abierta sobre el chorro, a grifo suelto, de las asociaciones verbales, para uso de los curanderos del Subconsciente", Ibid., p. 100.

${ }^{22}$ Alfonso Reyes, "Historia documental de mis libros. VI. El año de 1917”, UMex, 1955, núm. 9, p. 12.

${ }_{23}$ '"La poesía desde afuera", en $A l$ yunque, recogido en $A R O C$, t. 21, p. 322 . 
suficiente es bastante reciente. Tomando en cuenta este aparente rechazo de la autonomía del poema, se puede apreciar la injusticia de los que acusan a Reyes de frío formalismo. Pero hay cierta ambigüedad en la posición del autor. A veces, parece estar muy cerca de la poesía pura; otras veces, se aleja de esta tendencia que sí intentó expulsar del poema todo lo que no fuera esencia intrínseca. Pero si el mexicano puede apelar a una larga tradición para justificar la identificación entre poesía y autobiografía, los lectores modernos tenemos derecho a pedirle algo más al poema, pedirle que sea algo más que la huella de una circunstancia. Sentimos que el poema debe tener una intensa motivación interior en lugar de ser simplemente la respuesta a un diluido estímulo exterior.

Aunque una parte considerable de los versos de Reyes se expone a esta crítica (varios poemas que él llama "sociales" y que aparecen en la sección “Cortesía”' en Constancia poética), creo que hay muchos momentos de su poesía que trascienden las circunstancias exteriores para cobrar auténtico valor poético en el más exigente de los sentidos. El teórico que fue Reyes no siempre le hizo justicia al poeta.

Quisiera señalar una última consecuencia de las ideas del autor sobre la poesía. Una poética que tiende a sostener que todo poema es copia imperfecta de un arquetipo eterno, difícilmente puede admitir la idea de evolución temporal. De ahí que no se pueda hablar realmente de desarrollo en la poesía de Reyes, si exceptuamos tal vez los resabios de la retórica parnasiano-modernista en su primer libro de 1922. El lector acostumbrado al modelo romántico del libro como maduración orgánica de una persona, como biografía espiritual con sus sucesivas fases, queda perplejo ante una poesía que se concibe fuera del tiempo y en la cual todas las formas, los tonos y las preocupaciones esenciales están lo mismo en el primer libro que en el último. Se vuelve a presentar aquí la misma dicotomía notada antes: por un lado, la poesía se confunde con la vida y el poema no necesita más validez que la de ser un testimonio autobiográfico; por otro lado, la idea de que toda poesía aspira hacia una pureza atemporal ${ }^{24}$. Aunque no ne-

${ }^{24}$ En El deslinde [1944] (AROC, t. 14), Reyes distingue entre los diferentes grados de historicidad en la poesía, desde la relativa indiferenciación de poesía e historia en los orígenes de todas las culturas, hasta la anhelada separación de las dos en la poesía pura. La obra poética de Reyes se despliega entre estos dos extremos, sin identificarse con ninguno. Cuando sostiene que entre vida y obra hay una relación de interdependencia, de influencia y fertilización recíprocas, parece rechazar las dos posiciones extremas: por un lado, se 
cesariamente irreconciliables, estas dos nociones implican dos visiones encontradas que sólo se logran reconciliar en momentos privilegiados, momentos cuando el poema encarna en una arquitectura instantánea para volverse, en palabras de Reyes, "una escultura de aire"'25. Es decir: un auténtico poema debe tener la solidez permanente de la forma ceñida y mesurada ("escultura"), pero también la volatilidad dinámica y etérea de la sustancia de la vida ("aire"). Afortunadamente, estos momentos no son infrecuentes en su poesía. Pero insisto: esta poética inmóvil de la tradición eterna esconde una fascinación precisamente por ser extemporánea y ajena. Al leer a Reyes leemos toda una tradición poética, actualizada y revitalizada.

Se dirá que el clasicismo de Reyes es un anacronismo en el siglo $\mathrm{xx}$, pero habría que agregar que también lo es el clasicismo de un Eliot, un Valéry o un Borges. Precisamente por ser una estética de la eternidad en una época obsesionada por la temporalidad, por ser una "ruta vertical" que aspira a elevarse y liberarse de la cadena horizontal y lineal de la historia, por ser una visión armoniosa en una época de discordia, el clasicismo de Reyes asume sus paradójicas dimensiones como una desmesura, una heterodoxia.

niega a ver al arte como reflejo directo e inmediato de la vida (véase "La biografía oculta", en La experiencia literaria, recogido en AROC, t. 14, pp. 120122), e insiste con frecuencia en la distinción mallarmeana entre estado de alma (ideas) y poesía (un artefacto de palabras); por el otro, encuentra deficiente e inecesariamente empobrecedora la doctrina "purista" de la poesía como esencia destilada que resulta de la expulsión de todo lo relacionado con la vi$\mathrm{da}$, ya que toda obra literaria acarrea inevitablemente un "mínimo de realidad" ("La poesía desde afuera", p. 321). Sabemos incluso que frente al concepto de la poesía pura, "Alfonso Reyes propuso al final de su vida el de la "poesía total"" (Alfonso Rangel Guerra, Las ideas literarias de Alfonso Reyes, El Colegio de México, México, 1989, p. 265). Recién terminado el presente trabajo, me llega a las manos el libro de Rangel Guerra, en el cual hay una minuciosa reconstrucción y exposición de la teoría literaria de Reyes. Para una sucinta descripción de la visión de la poesía y del proceso de creación en la teoría literaria de Reyes, véanse especialmente las pp. 169-194 y 262-265.

${ }^{25} \mathrm{La}$ frase aparece en "Compás poético", una breve descripción de la poesía de Enrique González Martínez, recogida en Ancorajes, libro que forma parte del t. 21 de $A R O C$, p. 49. 
Una lectura atenta de Constancia poética, el tomo 10 de las Obras completas, revela la asombrosa riqueza y variedad de formas, metros, acentos y temas practicados por Reyes. Entre los géneros poéticos se destacan poesía cívica, épica, heroica, amorosa, bucólica o pastoril, dramática, religiosa (paradójicamente, ya que Reyes no es un autor de temple cristiano), poesía de circunstancias, y poesía para niños. A esta riqueza genérica hay que agregar la diversidad de formas poéticas - odas, elegías, sonetos, romances, coplas, cancioncillas, décimas, epigramas, glosas, seguidillas, formas que se acercan al haikú, y otras lúdicas como el acróstico y la adivinanza- y de diversas modalidades métricas desde el arte menor hasta el arte mayor, siendo las más preferidas el octosílabo del romance y el endecasílabo del soneto. Hay también varios experimentos logrados con el verso libre.

$\mathrm{Si}$ existe riqueza formal en esta poesía, no son menos variados los temas y los acentos. En lo temático: el país natal, la ciudad natal, la infancia, la familia, la geografía de México y de América, el amor (desde la idealización platónica hasta la sensualidad sensorial y el tímido erotismo), la muerte y la poesía misma ${ }^{26}$. Los tonos, en una auténtica interpenetración de lo popular y lo culto, abarcan varios extremos: seriedad y humor; solemnidad y burla; refinamiento y coloquialismo; lo público y lo privado; artificio y sencillez; cortesía y parodia. Si la abundancia acarrea el riesgo de cierta monotonía, esta saludable variedad funciona como buen antídoto. La imagen docta y erudita del humanista encuentra su mejor contrapeso en la incorporación de elementos humorísticos y populares y en el frecuente descenso hacia lo trivial.

Dentro de esta multiplicidad de temas y acentos, he decidido ocuparme de un elemento central y ordenador: la poética como tema de la poesía. Hay varios poemas que tienen como tema explícito a la poesía. Aquí, no me propongo un análisis exhaustivo de todos estos poemas sino una visión crítica de algunos de los más significativos. Uno de los más conocidos es "Teoría prosaica", escrita en 1931. Consta de tres partes desiguales. En la primera se comparan prácticas rústicas y populares de México y de Argentina. Los giros coloquiales y algunos regionalismos se combinan con referencias cultas, estableciendo así el tono y el tema

${ }^{26}$ Todos estos temas, con la extraña excepción de la poesía misma, están comentados en Florit, art. cit., pp. 240-248. 
del poema. La segunda parte contiene una declaración explícita:

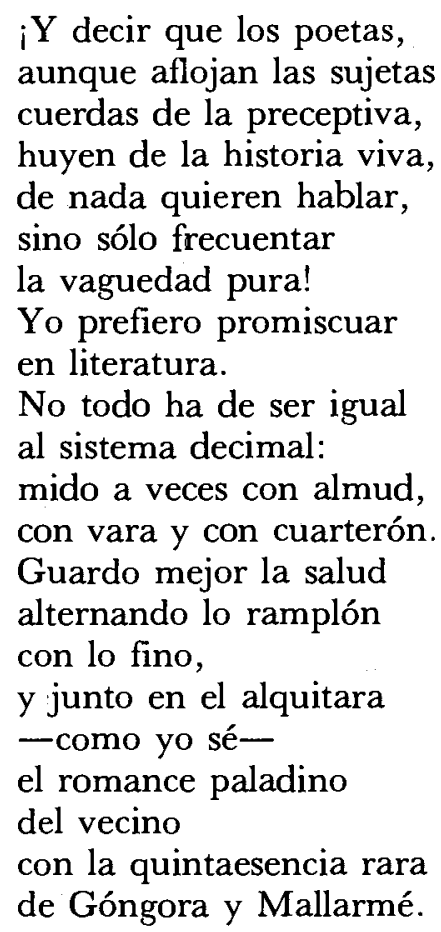

¡Y decir que los poetas, aunque aflojan las sujetas cuerdas de la preceptiva, huyen de la historia viva, de nada quieren hablar, sino sólo frecuentar la vaguedad pura! Yo prefiero promiscuar en literatura.

No todo ha de ser igual al sistema decimal: mido a veces con almud, con vara y con cuarterón. Guardo mejor la salud alternando lo ramplón con lo fino, $y$ junto en el alquitara - como yo séel romance paladino del vecino con la quintaesencia rara de Góngora y Mallarmé.

(pp. 131-132)

Alianza entre lo popular y lo culto, giros coloquiales y arcaísmos, pero todo destilado hasta alcanzar un equilibrio entre los polos opuestos, reconciliados en el poema. Formalmente el poema expresa esta alternancia en sus vaivenes entre una medida métrica regular (el octosílabo con rimas consonantes) y las bruscas rupturas de esta regularidad en los pies quebrados. La sonrisa irónica y burlona da al poema un tono unificado y en la ultima parte la metáfora culta de la destilación se transforma en la más terrestre de la fundición:

y el habla vulgar fundida

con el metal

del habla más escogida

-así entre cristiano y moro-,

hoy por hoy no cuadran mal:

así va la vida

y no lo deploro. 
En el prólogo al libro Otra voz, donde por primera vez apareció este poema, Reyes describe sus metas:

Estos poemas no van afinados en un solo tono de voz, pero en la mescolanza está el toque, el toque neurálgico, el toque de reacción [...] a veces me asusto de que pueda llegar la hora de la cristalización. Entonces, para sentirme vivo, hago versos a contrapelo, fuera de mi estilo habitual y un poco al sabor de la conversación, a modo de estrujón contra la estética (p. 497).

Esta introducción del prosaísmo y el coloquialismo, del humor y la ironía, le dan a Reyes pleno derecho a figurar en la historia de la antipoesía en Hispanoamérica. No fue el primero, ya que en 1925, siguiendo el modelo del poeta nicaragüense Salomón de la Selva, guiados ambos por Pedro Henríquez Ureña, Salvador Novo había introducido estos tonos en sus $X X$. poemas ${ }^{27}$.

$\mathrm{Si}$ “Teoría prosaica" representa dentro de la obra de Reyes el polo poroso de la "promiscuidad" y el principio de mestizaje temático y formal, en "Arte poética", un poema escrito en París seis años antes, se puede apreciar el otro extremo de la poética del autor, el polo de la pureza que huye de las contaminaciones de la vida:

Asustadiza gracia del poema:

flor temerosa, recatada en yema.

2

Y se cierra, como la sensitiva, si la llega a tocar la mano viva.

En "Consagración", un poema menos conocido que los dos anteriores y escrito en 1934, el tono irónicamente solemne es el instrumento de la desacralización y la profanación irreverente del recinto sagrado de la poesía, presente en el poema en la forma de la destinataria femenina - musa o Diosa:

Con tres compases de santa, de santa sin resplandor,

${ }^{27}$ Sobre los papeles de Henríquez Ureña, De la Selva y Novo como fundadores de lo que se llamaría después "antipoesía", véase JosÉ Emilio PACHECO, "Nota sobre la otra vanguardia", RevIb, 45 (1979), 327-334. 
bajaste de la peana, que es el milagro mayor.

Hoy te adoran las sandalias que aplastas con el talón; te adoran los candeleros que tiemblan en el salón,

y hasta la forma del aire, en el hueco que dejaste, donde se cuajó tu vida para siempre.

Ya no corres ni te vas: te matamos, te maté.

Anticipación de la antipoesía de Nicanor Parra, este poema es una paradójica afirmación de la eternidad del arte ("para siempre"), pero la perduración de la forma fija ("que te hice de cristal") depende de un ultraje. La eterna vida de la poesía (lugar común de la tradición) exige la destrucción de los símbolos y del léxico tradicionales. La innovación y la ruptura se convierten así en los cómplices heterodoxos de la tradición. Los nuevos acólitos de la divinidad poética son la nueva temática mundana ("sandalias" y "candeleros"). El poema es un homenaje y, simultáneamente, una profanación: para dar nueva vida a la poesía hay que matarla e inmovilizarla en el poema. Así, el asesinato de la musa tradicional es sinónimo del acto de fijar el poema, abstrayéndolo del flujo temporal. Victoria de lo moderno sobre la tradición, pero también reafirmación de la tradición.

En otros poemas, sin embargo, desaparecen el humor y la ironía. Domina aquí una voz mesurada y rítmicamente hipnótica que se dirige al arte a través del símbolo tradicional de la rosa, perfecta en su fragilidad fugaz:

Número soy de tu cuenta, danza de tu movimiento, y a la vez que tu remolque, ámbito soy de tu vuelo.

$$
\text { (p. 209) }
$$

El movimiento rítmico de estos espléndidos octosílabos ejemplifica el equilibrio dialéctico entre lo fijo y lo dinámico, entre destino 
y libertad, entre vuelo y contención. La balanza se expresa en la perfecta síntesis entre el gran movimiento interior - acentuación rítmica dactílica pero con cierta variación, en los versos segundo y tercero, entre los acentos fijos en la primera y séptima sílabasy el octosílabo del romance, la medida métrica que limita el movimiento sin suprimirlo.

En la danza del ritmo, el poeta asume su condición ambigua como cifra y espacio de encarnación de la poesía. No es que el yo poético se convierta en objeto de la corriente poética sino que dentro de los límites que fijan las leyes de la forma, él encuentra su espacio de libertad:

Mas yo que tus leyes sigo

$\mathrm{y}$ en tus aires me gobierno...

Hay concordia y equilibrio porque la rosa de la poesía es "maestra en ajustar / la voz con el pensamiento" (p. 209). Pero la acción de equilibrar no es un proceso exclusivamente racional: nace de una brújula interior, un instinto poético que no distingue entre "medir" y "sentir":

Perfecta rosa que adoro:

para implorarte no encuentro

sino medir las palabras

con los latidos del pecho.

(p. 210)

Esta balanza entre cerebro y pasión encuentra una formulación de intercambiabilidad mutua en el último terceto de un soneto dedicado a Eugenio Florit:

Es que el poeta cumple el mandamiento: hacer razones con el sentimiento $y$ dar en sentimiento las razones.

El ideal de una depuración esencial se expresa muy bien en "Silencio". Cabe notar que, lejos de las doctrinas puristas, el centro de depuración anhelado aquí es un punto de reconciliación entre poesía ("verso"), vida ("latido") y naturaleza ("universo"), un punto donde conviven lo fugaz y lo eterno: 
Cada vez menos palabras;

y cada palabra, un verso;

cada poema, un latido;

cada latido, universo.

Esfera ya reducida

a la norma de su centro,

es inmortal el instante

y lo fugitivo eterno.

(p. 214)

Las perfectas figuras geométricas que abundan en esta poesía pueden dar la impresión de fría racionalidad helénica, pero no es así. En el soneto "La verdad de Aquiles", por ejemplo, es significativo que el poeta hable de "una espiritual geometría" ( $p$. 417). Por otro lado, el comienzo de "Consejo poético" sugiere que número, cifra y medida son las perfectas formas platónicas (arquetipos eternos):

La cifra propongo; y ya

casi tengo el artificio, cuando se abre el precipicio de la palabra vulgar.

Las sirtes del bien y el mal, la torpe melancolía, toda la guardarropía de la vida personal, aléjalas, si procuras atrapar las formas puras.

Pero la segunda (casi) décima del poema nos lleva de esta pureza platónica (con su ideal del arte como esencia libre de las contaminaciones de la vida y lo sentimental) hasta un pitagorismo en el cual la estructura matemático-musical del universo acomoda lo emotivo dentro de una armonía más vasta:

¿La emoción? Pídela al número que mueve y gobierna al mundo. Templa el sagrado instrumento más allá del sentimiento.

Se ve que la "espiritual geometría" no es el dictado de la razón sino un acorde cósmico. 
En varios poemas hay una apelación a la voz de la contención para corregir un desequilibrio y restablecer la armonía perdida. "Otoñada" termina en una reprimenda a los excesos sentimentales de la voz lírica:

(Canción: esta vez divagas.

Ten cuenta con lo que dices.)

Estos dos últimos versos se distinguen de los demás versos del poema por el recurso del paréntesis, que funciona aquí como una manera de introducir otro discurso dentro del discurso original.

En "Un día", un conjunto de cuatro variaciones que siguen la progresión del día (noche $\rightarrow$ mañana $\rightarrow$ mediodía $\rightarrow$ crepúsculo), se procura expresar la armonía esencial de las cosas. Al final, la voz poética confía la comunicación del misterio a los sentidos y al silencio pero el poema termina con una invocación a la voz reflexiva, la voz de la sabiduría poética:

Yo no lo puedo decir, sé muy poco, no sé nada: es mejor que lo confíe a las sombras sosegadas, a las antenas del tacto, al silencio, a la mirada. ¡Vuela, pensamiento, y díle que calle y no diga nada!

(pp. 180-181)

El instinto poético de conciliación se presenta a veces como una brújula interior, equivalente a la "espiritual geometría" que restablece el equilibrio:

y no dejé que los goces

alteraran mis medidas.

Porque, entre los torbellinos

y las sirtes enemigas

nunca me engañó la brújula

que en el corazón traía.

Lo que me hurtaba el dolor, la pluma lo devolvía. 
La necesidad de dar forma a lo informe, de encauzar el material emotivo, constituye el tema de varias composiciones. El impulso vital de los sentimientos es ahora la loca carrera del caballo desenfrenado, pero el poeta es el jinete que toma las riendas, controla y orienta el libre vuelo, inmovilizando la pujanza dinámica:

Pasa el jinete del aire montado en su yegua fresca, y no pasa: está en la sombra repicando sus espuelas.

(p. 387)

O, como en este otro ejemplo, menos logrado por ser más explícito:

Me hacían jinete y versero

el buen trote y sus octosílabos

y el galope de arte mayor, mientras las espuelas y el freno me iban enseñando a medir el valor.

En otros poemas se articula la misma idea de dar forma a lo informe y lo potencialmente caótico mediante la metáfora de un poderoso río que hay que encauzar:

Ceñí las aguas del bullente río como por duro cauce bien labrado, y pasmo fue si cada desvarío halló la ley del oportuno vado.

Los sólidos endecasílabos del soneto -con sus rimas consonantes que ejemplifican en el nivel formal la coherencia y la estabilidad de la soldadura poética- se repiten en otro poema menos logrado, tal vez por su tono de preceptiva didáctica:

Había que buscar la ruta cierta y ceñir el desborde con el dique.

Como sucede con frecuencia en Reyes, los endecasílabos del soneto tienen cierta rigidez si se comparan con el libre vuelo y la gran riqueza rítmica del arte menor de los romances. Indudable- 
mente, se siente más libre en el romance, por ser ésta una forma de honda raigambre popular, una forma "porosa" que acepta sin discriminación elementos narrativos y líricos, y que se adapta con idéntica soltura al refinamiento culto o a la burla popular. "No hay asunto humilde para el poeta", escribió Reyes en otro lugar $^{28}$. Asimismo, en unas notas a los Romances del Río de Enero, apunta:

El romance nos transporta a la mejor época de la lengua, trae evocaciones tónicas; la lengua, desperezada, ofrece sola sus recursos. Además - ventaja para aprovecharla ahora mismo- el romance deja entrar en la voz cierto tono coloquial, cierto prosaísmo que se nos ha pegado en esta época, al volver a las evidencias (p. 401).

Si el arte poético es el arte de dar forma a lo que amenaza con desbordarse y salirse del orden del poema, en unas pocas composiciones Reyes intenta - con escasa fortuna- expresar el universo caótico donde se rompe toda noción de equilibrio y proporción:

¡Horror de la palabra ya vacía, aberración del acto sin oriente, la brújula sin norte, anomalía de ver rodar la mole sin la mente!

Y el alma, que se queda atrás, no fía ya ni en las normas, ni en las estructuras ni en la armonía, ni en la jerarquía.

(pp. 451-452)

Y digo que no se logra expresar el caos porque la forma métrica sigue siendo el endecasílabo con sus rimas convencionales. Es cierto que los dos encabalgamientos y las disrupciones de la sintaxis fluida ayudan en parte a transmitir la sensación de desorden, pero este desorden está insertado dentro de un molde formal de orden. Sin embargo, estos son momentos muy aislados en la obra de Reyes y constituyen siempre una "anomalía", como se dice en los versos citados.

La posición más característica en Reyes es permitir una ex-

28“"Fragmentos del arte poética", en Ancorajes, ed. cit., p. 57. 
ploración de lo misterioso y lo desconocido pero con arte, como se dice al final de un soneto:

y despacio y con arte, a ver si exploras esa zona hechizada que limita la inefable cortina de las horas.

Cuando esta poesía se permite el raro privilegio de navegar en las oscuras aguas del sueño, se mantiene en un estado de desvelada vigilancia para no ceder a la tentación de perderse. Esta resistencia se expresa en un soneto neobarroco, inspirado en un verso de Góngora: "La brújula del sueño vigilante”. Abundan aquí varias marcas estilísticas del barroquismo (antítesis, oxímo-

- ron y paradoja), y hay un verso que podría ser de Xavier Villaurrutia, el "dormido despierto"' que empleó varios recursos retóricos de la poesía barroca en su obra, pero es un verso característico de la postura estética de Reyes: "y voy despierto cuando más dormido" (p. 447).

En todas estas muestras de la poética como tema de la poesía, la visión estética aspira a fijar un momentáneo equilibrio de perfección, un instante suspendido del desgaste temporal, como si fuera un centro autosuficiente sostenido en el aire por el ímpetu centrípeto de la forma. El movimiento detenido sugiere una eternidad fugaz, un ritmo inmovilizado por la armonía de sus proporciones y medidas. Los mejores poemas del autor logran articular maravillosamente bien lo que Reyes concebía como el deber del poeta: "eternizar cada instante, expresando esa proporción de luz y sombra por la que cada instante atraviesa" 29 .

$\mathrm{Al}$ emprender una valoración de la poesía de Reyes, nos enfrentamos con el problema de la abundancia. Sabemos que el autor estuvo opuesto al sentido antológico pero su posición fue ambigua puesto que Constancia poética es ya un primer intento tímido de hacer la antología que tanto necesitamos. Una de las motivaciones del tomo fue descrito por el poeta en el prólogo como "el intentar una primera selección' '(p. 9). Ahora, a 30 años de distancia de la primera edición, es preciso proceder a una depuración mucho más radical para beneficio del propio poeta y, sobre todo, de los lectores modernos ${ }^{30}$.

29' "La poesía desde afuera", p. 322.

${ }^{30}$ Por otra parte, se sabe que el propio poeta se dio cuenta, en los ultimos años de su vida, de la necesidad de ofrecer breves selecciones de su poesía. 
Reyes creía que su obra estaba animada por el solo propósito de expresar "la total manifestación de una existencia", pero no todos los aspectos de esa existencia son de igual interés o relevancia para un lector de poesía. Hay muchas composiciones de la extensa sección llamada "Cortesía", que agrupa la poesía de circunstancias o poemas "sociales" del autor, que no sobrevivirían la prueba de una criba antológica. Varios de estos poemas no trascienden las circunstancias de su composición ${ }^{31}$. Algunos dirán que revelan un aspecto importante y nada deleznable de la persona de Reyes: su bondadosa cordialidad y su generosa cortesía. Es cierto, pero creo que el tomo se beneficiaría si no tuviera que cargar con tanto material de motivación extrínseca o anecdótica.

Una buena selección del tomo Constancia poética resultaría en un libro menos voluminoso, menos repetitivo pero más esencial y más convincente. Se vería, entonces, que esta poesía no carece de riesgos sino que asume como su riesgo mayor el alcanzar la perfección que ella misma se exige. Se apreciaría también que la precisión y la nitidez, si bien no permiten explorar el lado oculto y oscuro del ser, sí logran evitar, en cambio, toda ampulosidad y vaguedad retóricas. No se equivocaba el autor al hablar de la temprana influencia parnasiana en sus versos: "Ella rectificó el romanticismo amorfo de la adolescencia" (p. 11). Leer al mejor Reyes significa, en palabras de Paz, "una lección de claridad y transparencia"'32. Es, sobre todo, un buen ejercicio de cuestionamiento de nuestras limitadas preconcepciones modernas.

Véase el "Propósito" que Reyes escribió en 1957 para el proyectado libro Recordación poética, breve antología que podemos leer hoy en Alfonso REYES, $A n$ tología personal, ed., palinodia y notas de Ernesto Mejía Sánchez, Martín Casillas Editores, México, 1983, pp. 23-46. En el “Prólogo"' a Obra poética (1952), reproducido en Constancia poética (1959), el autor ya había reconocido la necesidad de una antología, pero se mostró renuente a hacerla él mismo: "Aún no me atrevo a proponer mi verdadera antología. Tal vez ello, si ha de ser algun día, ni siquiera me corresponda. El criterio del autor y el del lector nunca pueden confundirse del todo. Y confieso que la sola palabra "antología» me amedrenta, y la hallo poco recomendable para aplicada a la obra propia. ¿Quién puede estar cierto de ofrecer flores y no espinas, antología y no acantología?" (p. 9).

${ }^{31}$ Vale la pena subrayar, sin embargo, que unos cuantos poemas de la sección "Cortesía" se cuentan entre los mejores del autor. Véanse, por ejemplo, "Candombe porteño" y "Para un mordisco", en Constancia poética, pp. 248-249 y 276-277.

32 Octavio Paz, El laberinto de la soledad, $2^{\mathrm{a}}$ ed., rev. y aum., FCE, México, 1959, p. 146. 
Por su diversidad temática, formal y acentual, por el acceso que nos permite a toda una tradición poética, revitalizada y actualizada, la poesía de Alfonso Reyes merece un lugar destacado en el ámbito de la poesía moderna en lengua española. Vale la pena detenerse en las características que atraviesan su poesía porque no son tan comunes en la literatura mexicana o hispanoamericana. Son cualidades que sólo se reúnen en los más grandes: gracia, sensualidad, donaire, naturalidad, humor, agilidad, frescura, :juego, fragilidad, encanto diáfano y la sorpresa de lo inesperado. Existe también en Reyes un oído fino, atento a la materialidad del significante, a lo que él mismo denominó "la belleza física de las palabras" 33 . En estos tiempos de redescubrimiento de la oralidad como fenómeno artístico, la impresión oral de sus poemas - una oralidad que es fruto de la fusión de lo popular y lo culto- es una saludable reacción en contra del concepto más intelectual, visual y espacial de "escritura". Más que escritura, la poesía, para Reyes, es habla regida por ritmo y musicalidad.

Si se lee no según nuestras estrechas expectativas contemporáneas, como lo ha hecho gran parte de la crítica, sino por lo que ella misma ofrece, entonces se verá que la poesía de Alfonso Reyes sigue proporcionando, en sus mejores momentos, una verdadera experiencia estética: sigue siendo, como él mismo quería, "la ruta vertical"'34.

Anthony Stanton

El Colegio de México

${ }^{33}$ Citado en Florit, art. cit., p. 227.

${ }^{34}$ Una versión más breve de este texto se leyó en la mesa redonda "Alfonso Reyes: entre la literatura y la crítica" el 31 de mayo de 1989 en El Colegio de México. Agradezco las oportunas observaciones de mi colega Rose Corral, quien revisó la primera versión de este texto. 